Curr Opin Gastroenterol. 2016 May ; 32(3): 189-194. doi:10.1097/MOG.0000000000000262.

\title{
Cell Therapy in Chronic Liver Disease
}

\author{
Clara Nicolas, \\ William J. von Liebig Center for Transplantation and Clinical Regeneration, Mayo Clinic, \\ Rochester, MN, USA., 507-284-1606

\section{Yujia Wang, and} \\ William J. von Liebig Center for Transplantation and Clinical Regeneration, Mayo Clinic, \\ Rochester, MN, USA
}

\section{Scott L. Nyberg}

Department of Surgery, Mayo Clinic, Rochester, MN, USA; William J. von Liebig Center for Transplantation and Clinical Regeneration, Mayo Clinic, Rochester, MN, USA

\section{Abstract \\ Purpose of review-To date, the only curative treatment for end-stage liver disease is liver transplantation, which is limited by the shortage of available organs. Cell therapy, in the form of cell transplantation or cell-based extracorporeal support devices, may in the future offer an alternative to transplantation, or at least provide liver function support as a bridging therapy until surgery may be performed. The purpose of this review is to highlight the most recent advances made in the field of cell therapy and regenerative medicine for the treatment of chronic liver disease (CLD).}

Recent findings-After hepatocyte transplantation, long-term engraftment in the liver and spleen may be achieved, which can be stimulated through preconditioning, multiple infusions, and inflammatory response blockade. Mesenchymal stem cells are promising candidates for cell transplantation, as they have been shown to reduce liver fibrosis and support endogenous regeneration. Adipose tissue-derived stem cells are also being tested in this setting, due to their ready availability. Bioartificial liver (BAL) devices are being built that allow for effective preservation of hepatocytes, and one such device has recently demonstrated survival benefit in a porcine model of liver failure.

Summary-Cell transplantation of primary hepatocytes or stem cell-derived hepatocyte-like cells (HLCs) for the treatment of CLD holds promise. BAL systems may in the future be able to bridge acute-on-chronic liver failure patients to liver transplantation.

\section{Keywords}

chronic liver disease; cell therapy; bioartificial liver

\footnotetext{
*Corresponding author.

Conflicts of interest: The authors report no conflict of interest.
} 


\section{Introduction}

Chronic liver disease (CLD), or cirrhosis, is the gradual destruction of liver parenchyma over time as a result of any chronic injury to the liver. Numerous different pathophysiological mechanisms result in a final common pathway of functioning hepatic tissue being replaced by scar tissue, or fibrosis, leading to impaired hepatic function (1). For years, the medical treatment of CLD has been centered on symptom control and the prevention of complications. Although by definition cirrhosis cannot be resolved completely, it is possible to slow, halt, and even reverse progression of fibrosis (2). Nevertheless, once decompensation becomes refractory to medical therapy the only proven treatment for endstage liver disease is liver transplantation regardless of original etiology (3).

Liver transplantation as a form of definite treatment for CLD, however, is limited by the shortage of organs available for transplantation. As the demand for donor organs grows, therapeutic alternatives to liver transplantation must be sought out. One such possible alternative is cell therapy, or the administration of live, whole cells for the treatment of a disease. The role that cell therapy may play in the treatment of CLD is two-fold. By stimulating endogenous regeneration and inhibiting fibrosis, cell therapy may curb disease progression, thus ideally eliminating the need for liver transplantation (4). In the cases where liver transplantation cannot be avoided, cell therapy may serve as a means for liver function support and act as a bridge to surgery, in theory decreasing waitlist mortality rates.

The aim of this review is to highlight the most recent advances made in the field of cell therapy and regenerative medicine for the treatment of CLD.

\section{Cell Therapy}

Cells have the ability to perform complex biological functions, and at the same time their behavior can be engineered (5). Cell-based therapeutics attempt to harness this power to treat problems that fall beyond the scope of traditional pharmacology. These cells can be administered directly into the patient's body in a procedure known as cell transplantation, but may also be used to populate extracorporeal assist devices (4). Cell therapy can be categorized according to the type of cell used and its duration within the body (Table 1).

\section{Primary Hepatocytes}

Cell therapy for CLD has traditionally been based on the use of primary hepatocytes. Unfractionated, genetically unmodified hepatocyte transplantation through splenic or portal venous infusion has been tested in both animal models and humans, with modest reductions in ammonia levels and encephalopathy (8). However, there are several important barriers to the use of human hepatocytes.

Engraftment of transplanted cells in the liver parenchyma can be problematic, as a large number of the delivered cells are cleared by activation of the inflammatory cascade. Numerous methods for liver preconditioning have been studied to achieve more successful liver repopulation (9). In a recent study, the administration of multiple hepatocyte infusions, coupled with pharmacological blockage of the inflammatory response, has shown promise in 
decreasing transplanted cell clearance, improving engraftment, and accelerating repopulation (10). Hepatocytes have the ability to engraft and survive for extended periods of time in the spleen, as well as in the liver: in a five-year follow-up study of intrasplenic hepatocyte transplantation for acute-on-chronic liver failure, living hepatocyte signals were observed in the spleen at 48 months post-transplantation (11).

The most important limitation to the use of human hepatocytes is isolation of a sufficient quantity of high-quality, metabolically active cells. Hepatocytes are typically harvested from livers not suitable for transplantation, with the variability in quantity and quality that this entails (12). Furthermore, storage of hepatocytes is not without its complications, as these cells are sensitive to freeze-thaw damage so that viability and engraftment are affected by cryopreservation (13). Consequently, alternative sources of cells are being actively sought after.

One such possible alternative hepatocyte source is xenotransplantation of animal-derived hepatocytes, namely porcine cells. A number of studies have shown hepatocyte engraftment and function across a species barrier, but while the exclusion of vascular structures may address some of the immunological issues associated with xenotransplantation, the possibility of xenozoonosis remains (14). Another viable option in the future may be the use of fumarylacetoacetate hydrolase (FAH) deficient pigs as incubators for in vivo expansion of human hepatocytes, as in utero cell transplantation can lead to postnatal engraftment of functional human cells in the xenogeneic recipient, possibly allowing for large-scale expansion of human hepatocytes in genetically-engineered pigs (15). Stem cells are also a potential source of hepatocyte-like cells (HLCs), and will be discussed in the following section.

However, a recent study suggested that in an FAH-deficient mouse chronic liver failure model adult hepatocytes were superior to other cell lines in lessening liver injury, recovering liver function, and promoting liver regeneration (16). Another recent study showed that periportal hepatocytes are capable of replenishing the entire hepatic parenchyma after chronic hepatocyte damage without giving rise to hepatocellular carcinoma, and therefore may represent a relevant method to restore tissue function while avoiding tumorigenesis (17). A phase I-II matched case-control study of human fetal liver cell transplantation has also been published that shows significant difference in MELD and Child-Pugh scores for those patients receiving intrasplenic fetal hepatocyte infusions as compared to standard therapy (18).

\section{Stem Cells}

Stem cells have various potential applications in the treatment of liver disease: modulation of the liver's regenerative processes to reduce scarring in cirrhosis, down-regulation of immune-mediated liver damage, and supply of HLCs for cell transplantation or use in extracorporeal bioartificial liver systems (19). Fetal hepatic stem cells, or hepatoblasts, have the advantage of being less immunogenic and more propagative than adult stem cells, but their isolation and cryopreservation poses a greater challenge (20). It has been suggested fetal liver stem cells can replace liver mass with advanced cirrhosis to a greater extent than 
hepatocytes (21). Human fetal biliary tree stem cells have been tested in a small number of cirrhosis patients, with clinical and biochemical improvement (22). Liver progenitor cells and the cell signaling involved in their reconstitution of liver parenchyma is still being studied, so that in the future extracellular matrix factors may be used to facilitate their induction (23). Human induced pluripotent stem cells have also emerged as a way of bypassing the ethical and immune concerns associated with the use of embryonic stem cells, and efforts are being made to achieve significant liver repopulation through their transplantation (24).

The cells that have shown the most promise for the treatment of cirrhosis, however, are mesenchymal stem cells (MSCs). MSCs are able to provide both metabolic and trophic support due to their capacity for hepatocytic differentiation, as well as their secretion of antiinflammatory, anti-apoptotic, immunomodulatory, and pro-proliferative factors (25) (Figure 1). This means that aside from restoring liver function through substitution of damaged tissue, MSCs are able to suppress lymphocyte activity (26) and avoid further immune destruction of the liver, as well as stimulate endogenous regeneration through their paracrine effects (27-29). In rat liver cirrhosis models, bone marrow-derived MSC (BM-MSC) therapy decreased alanine and aspartate aminotransferase, albumin, hyaluronic acid, laminin, and procollagen type III levels significantly through either portal or peripheral venous administration (30), and resulted in histological attenuation of liver fibrosis (31). A study by the same group analyzed the effects of autologous BM-MSC administration in alcoholic cirrhosis patients, demonstrating histological improvement as measured by the Laennec fibrosis system, as well as a significant reduction in transforming growth factor- $\beta 1$, type 1 collagen and a-smooth muscle actin levels (32). Before MSCs reach clinical application a number of issues must be addressed. Recent meta-analyses have concluded that although no serious side effects or complications have been reported, and therefore MSC therapy may be considered safe, study methodology is in general deficient, making multicenter randomized prospective trials necessary to develop standardized protocols for MSC transplantation (33, 34). Optimal cell dosage, route of administration, number of injections, and therapeutic timing have yet to be determined (35), and the questions of MSC therapy's long-term effectiveness and potential tumorigenic risk have yet to be answered (36).

Other cell lines have also been evaluated. In fact, bone marrow-derived CD45 cells have been suggested to be superior candidates to adipose tissue-derived MSCs for the treatment of liver cirrhosis due to their higher capacity for structural and functional improvement of a CCl4-induced fibrotic liver mouse model (37). Intrahepatic transplantation of adipose tissuederived stem cells has also been proposed as a therapeutic approach for the treatment of NAFLD, as it may reduce lipid metabolism and oxidative stress, as well as improve liver function (38). A phase I/IIa clinical trial testing intrahepatic injection of these cells for the treatment of cirrhosis will begin shortly (39). Similarly, transplantation of human adipose tissue-derived multi-lineage progenitor cells in a CCl4-injured mouse model was shown to be linked to a reduction in liver fibrosis, measured through Sirius Red staining, as well as in serum glutamic pyruvate transaminase and total bilirubin levels (40). These studies show that stem cells may be a viable alternative to the use of primary hepatocytes in CLD. 


\section{Cell-based Extracorporeal Support Devices}

Whether primary hepatocytes, immortalized cell lines, or stem cell-derived HLCs are used, cell-based extracorporeal support devices are an alternative to cell transplantation for the treatment of acute-on-chronic liver failure (ACLF). ACLF is defined as an acute deterioration in liver function in patients with preexisting cirrhosis (41), and is associated with organ failure and high mortality rates (42). The goal of extracorporeal support systems is to maintain liver function in order to bridge the patient until a liver is available for transplantation or until the native liver is allowed to spontaneously recover through endogenous regeneration (43). In the case of ACLF, the need for liver transplantation in the long-term will most likely remain due to the underlying CLD, but extracorporeal support therapy may in the future be used to increase survival during acute decompensation. Both artificial and bio-artificial devices are being developed for this purpose.

Artificial liver support systems (ALSS) contain no cellular material, and therefore remove toxic substances from the blood through albumin dialysis without sustaining synthetic liver function (44). Studies involving ALSS such as MARS and Prometheus have shown improvements in bilirubin levels and hepatic encephalopathy, but none have demonstrated survival benefit (45). Research in this area is still active, and efforts are being made to improve these devices' capacity for albumin dialysis and endotoxemia reduction $(46,47)$. On the other hand, bioartificial liver (BAL) support systems (Figure 2) are able to better simulate liver function by virtue of protein synthesis and ureagenesis, as well as blood detoxification, through the incorporation of live, functioning hepatocytes into the device (48).

As discussed earlier, hepatocyte culture is not without its difficulties due to the tendency of these cells to dedifferentiate in vitro (49). Consequently, many studies have focused on developing hepatocyte carriers that allow for high seeding densities and hepatocyte-specific functions, such as macroporous cryogels and blood-compatible polymers $(50,51)$, as well as on methods of monitoring hepatocyte status in bioreactors in order to improve function and viability (52). Microcapsule-based bioreactors are being built that may in the future be incorporated into the design of BAL systems $(53,54)$. Another method for hepatocyte preservation within the BAL is the use of spheroids. Earlier this year, a spheroid reservoir BAL was tested in a porcine model of drug-induced acute liver failure, demonstrating a significant survival benefit when compared to no-cell device therapy or standard therapy alone (55).

The availability of primary human hepatocytes is also an issue. A recent study showed no transmission of porcine endogenous retrovirus following treatment with a hybrid BAL containing porcine hepatocytes, opening the door to the use of these cells for extracorporeal liver support in humans (56). Stem cells may also be a viable option for the replacement of primary hepatocytes (57). Out of the two bioartificial liver devices with the most extensive human trials, the Extracorporeal Liver Assist Device (ELAD) uses C3A human hepatoblastoma cells, while HeptaAssist uses porcine hepatocytes (58). None of the randomized controlled trials have shown survival benefit with either of these devices to date, and meta-analysis results are inconclusive $(59,60)$. More studies are necessary to evaluate 
the effectiveness and safety of the new generation of BAL systems in humans, and to identify the optimal cell line to supply it with (61).

\section{Conclusions}

Cell therapy in CLD works by supporting liver function and curbing fibrosis while endogenous regeneration takes place or as a bridge to liver transplantation. It can involve cell transplantation or BAL devices, using either primary hepatocytes or stem cell-derived HLCs. Current strategies focus on effective engraftment and in vitro preservation; efforts are also being made to find alternatives to hepatocytes, such as MSCs, with immunomodulative properties and trophic paracrine activity. Standardized protocols must be developed to obtain more robust clinical data on cell transplantation. In the case of BAL systems, clinical studies have yet to show survival benefit in humans with ACLF.

\section{Acknowledgments}

None.

Financial support and sponsorship: None.

\section{References}

1. Czaja AJ. Hepatic inflammation and progressive liver fibrosis in chronic liver disease. World $\mathbf{J}$ Gastroenterol. 2014; 20(10):2515-32. [PubMed: 24627588]

2. Pellicoro A, Ramachandran P, Iredale JP, Fallowfield JA. Liver fibrosis and repair: immune regulation of wound healing in a solid organ. Nature reviews. 2014; 14(3):181-94.

3. Poordad FF. Presentation and complications associated with cirrhosis of the liver. Curr Med Res Opin. 2015; 31(5):925-37. [PubMed: 25697811]

4. Bartlett DC, Newsome PN. Hepatocyte cell therapy in liver disease. Expert Rev Gastroenterol Hepatol. 2015; 9(10):1261-72. [PubMed: 26212798]

5. Fischbach MA, Bluestone JA, Lim WA. Cell-based therapeutics: the next pillar of medicine. Sci Transl Med. 2013; 5(179):179ps7.

6. Bhatia SN, Underhill GH, Zaret KS, Fox IJ. Cell and tissue engineering for liver disease. Sci Transl Med. 2014; 6(245):245sr2. [PubMed: 25031271]

7. Culme-Seymour EJ, Davie NL, Brindley DA, Edwards-Parton S, Mason C. A decade of cell therapy clinical trials (2000-2010). Regen Med. 2012; 7(4):455-62. [PubMed: 22817619]

8. Fisher RA, Strom SC. Human hepatocyte transplantation: worldwide results. Transplantation. 2006; 82(4):441-9. [PubMed: 16926585]

9. Forbes SJ, Gupta S, Dhawan A. Cell therapy for liver disease: From liver transplantation to cell factory. J Hepatol. 2015; 62(1 Suppl):S157-69. [PubMed: 25920085]

10**. Viswanathan P, Kapoor S, Kumaran V, Joseph B, Gupta S. Etanercept blocks inflammatory responses orchestrated by TNF-alpha to promote transplanted cell engraftment and proliferation in rat liver. Hepatology. 2014; 60(4):1378-88. This study opens a new pharmacologic approach to increase the effectiveness of cell delivery and engraftment after transplantation through blocking of the inflammatory cascade with a pre-existing, FDA approved TNF-a antagonist. [PubMed: 24844924]

11**. Wang F, Zhou L, Ma X, Ma W, Wang C, Lu Y, et al. Monitoring of intrasplenic hepatocyte transplantation for acute-on-chronic liver failure: a prospective five-year follow-up study. Transplantation proceedings. 2014; 46(1):192-8. This study demonstrates long-term engraftment of hepatocytes in the spleen, and describes a method for the detection of these cells through MRI that will allow for monitoring of transplanted cells. Few studies have been successful in 
monitoring live cells after transplantation, or have this extended a follow-up. [PubMed: 24507050]

12. Huebert RC, Rakela J. Cellular therapy for liver disease. Mayo Clinic proceedings. 2014; 89(3): 414-24. [PubMed: 24582199]

13. Ferrer JR, Chokechanachaisakul A, Wertheim JA. New Tools in Experimental Cellular Therapy for the Treatment of Liver Diseases. Curr Transplant Rep. 2015; 2(2):202-10. [PubMed: 26317066]

14. Zhou H, Liu H, Ezzelarab M, Schmelzer E, Wang Y, Gerlach J, et al. Experimental hepatocyte xenotransplantation--a comprehensive review of the literature. Xenotransplantation. 2015; 22(4): 239-48. [PubMed: 25950141]

15. Fisher JE, Lillegard J, McKenzie T, Rodysill B, Wettstein P, Nyberg S. In utero transplantation allows for postnatal engraftment of human hepatocytes in pigs. Liver Transplantation. 2013; 19:328-35. [PubMed: 23280879]

16. Sun K, Xie X, Xie J, Jiao S, Chen X, Zhao X, et al. Cell-based therapy for acute and chronic liver failures: distinct diseases, different choices. Sci Rep. 2014; 4:6494. [PubMed: 25263068]

17. Font-Burgada J, Shalapour S, Ramaswamy S, Hsueh B, Rossell D, Umemura A, et al. Hybrid Periportal Hepatocytes Regenerate the Injured Liver without Giving Rise to Cancer. Cell. 2015; 162(4):766-79. [PubMed: 26276631]

18*. Pietrosi G, Vizzini G, Gerlach J, Chinnici C, Luca A, Amico G, et al. Phases I-II Matched CaseControl Study of Human Fetal Liver Cell Transplantation for Treatment of Chronic Liver Disease. Cell Transplant. 2015; 24(8):1627-38. This trial has shown that intrasplenic injection of human fetal liver cells is safe and well-tolerated in end-stage liver disease patients, and has a positive effect on both MELD scores and encephalopathy. [PubMed: 24971879]

19. Forbes SJ, Newsome PN. New horizons for stem cell therapy in liver disease. J Hepatol. 2012; 56(2):496-9. [PubMed: 21798218]

20. Habeeb MA, Vishwakarma SK, Bardia A, Khan AA. Hepatic stem cells: A viable approach for the treatment of liver cirrhosis. World J Stem Cells. 2015; 7(5):859-65. [PubMed: 26131316]

21*. Yovchev MI, Xue Y, Shafritz DA, Locker J, Oertel M. Repopulation of the fibrotic/cirrhotic rat liver by transplanted hepatic stem/progenitor cells and mature hepatocytes. Hepatology. 2014; 59(1):284-95. This study suggests that hepatic stem cells are able to achieve a more successful repopulation of the liver than mature hepatocytes, and therefore may be a superior cell line for cell transplantation. [PubMed: 23840008]

22*. Cardinale V, Carpino G, Gentile R, Napoletano C, Rahimi H, Franchitto A, et al. Transplantation of human fetal biliary tree stem/progenitor cells into two patients with advanced liver cirrhosis. BMC Gastroenterol. 2014; 14:204. This study represents proof of concept that isolation of human fetal biliary tree stem cells is feasible, and that these cells are able to be infused safely into the advanced cirrhosis patient. [PubMed: 25471120]

23. Best J, Manka P, Syn WK, Dolle L, van Grunsven LA, Canbay A. Role of liver progenitors in liver regeneration. Hepatobiliary Surg Nutr. 2015; 4(1):48-58. [PubMed: 25713804]

24*. Zhu S, Rezvani M, Harbell J, Mattis A, Wolfe A, Benet L, et al. Mouse liver repopulation with hepatocytes generated from human fibroblasts. Nature. 2014; 508(7494):93-7. This group has been able to differentiate hepatocytes from human fibroblasts through induced multipotent progenitor cells by shortening the reprogramming protocol to avoid pluripotency. After achieving liver repopulation in a mouse model, they demonstrated hepatocyte function levels similar to those of human adult primary hepatocytes. [PubMed: 24572354]

25. Christ B, Bruckner S, Winkler S. The Therapeutic Promise of Mesenchymal Stem Cells for Liver Restoration. Trends Mol Med. 2015

26. Qu M, Cui J, Zhu J, Ma Y, Yuan X, Shi J, et al. Bone marrow-derived mesenchymal stem cells suppress NK cell recruitment and activation in PolyI:C-induced liver injury. Biochemical and biophysical research communications. 2015; 466(2):173-9. [PubMed: 26342798]

27. Liu WH, Song FQ, Ren LN, Guo WQ, Wang T, Feng YX, et al. The multiple functional roles of mesenchymal stem cells in participating in treating liver diseases. J Cell Mol Med. 2015; 19(3): 511-20. [PubMed: 25534251]

28**. Tang WP, Akahoshi T, Piao JS, Narahara S, Murata M, Kawano T, et al. Basic fibroblast growth factor-treated adipose tissue-derived mesenchymal stem cell infusion to ameliorate liver cirrhosis 
via paracrine hepatocyte growth factor. J Gastroenterol Hepatol. 2015; 30(6):1065-74. The impact of this study is two-fold: it shows that basic fibroblast growth factor may be used to enhance the therapeutic effect of mesenchymal stem cells, and at the same time that the effect of these cells is clearly related to their own secretion of hepatocyte growth factor. [PubMed: 25639333]

29*. Tan CY, Lai RC, Wong W, Dan YY, Lim SK, Ho HK. Mesenchymal stem cell-derived exosomes promote hepatic regeneration in drug-induced liver injury models. Stem Cell Res Ther. 2014; 5(3):76. Similarly to the previous reference, this study focuses on the practical implications of the hepatoprotective paracrine effects of mesenchymal stem cells, in this case through the use of mesenchymal stem cell-derived exosomes. [PubMed: 24915963]

30*. Song YM, Lian CH, Wu CS, Ji AF, Xiang JJ, Wang XY. Effects of bone marrow-derived mesenchymal stem cells transplanted via the portal vein or tail vein on liver injury in rats with liver cirrhosis. Exp Ther Med. 2015; 9(4):1292-8. The importance of this study is predicated on the fact that a similar effect was observed with portal vein and tail vein administration of these cells, suggesting that peripheral venous administration is a more convenient and equally effective route for cell transplantation. [PubMed: 25780424]

31. Jang YO, Kim MY, Cho MY, Baik SK, Cho YZ, Kwon SO. Effect of bone marrow-derived mesenchymal stem cells on hepatic fibrosis in a thioacetamide-induced cirrhotic rat model. BMC Gastroenterol. 2014; 14:198. [PubMed: 25425284]

32*. Jang YO, Kim YJ, Baik SK, Kim MY, Eom YW, Cho MY, et al. Histological improvement following administration of autologous bone marrow-derived mesenchymal stem cells for alcoholic cirrhosis: a pilot study. Liver Int. 2014; 34(1):33-41. This phase II trial also shows that mesenchymal stem cell therapy may result in histological attenuation of liver fibrosis in humans. Liver fibrosis may also be quantified through the measurement of cirrhosis-related factors, such as transforming growth factor- $\beta 1$, type 1 collagen, and $a$-smooth muscle actin. [PubMed: 23782511]

33. Pan XN, Zheng LQ, Lai XH. Bone marrow-derived mesenchymal stem cell therapy for decompensated liver cirrhosis: a meta-analysis. World J Gastroenterol. 2014; 20(38):14051-7. [PubMed: 25320545]

34. Kim G, Eom YW, Baik SK, Shin Y, Lim YL, Kim MY, et al. Therapeutic Effects of Mesenchymal Stem Cells for Patients with Chronic Liver Diseases: Systematic Review and Meta-analysis. J Korean Med Sci. 2015; 30(10):1405-15. [PubMed: 26425036]

35. Eom YW, Kim G, Baik SK. Mesenchymal stem cell therapy for cirrhosis: Present and future perspectives. World J Gastroenterol. 2015; 21(36):10253-61. [PubMed: 26420953]

36. Berardis S, Dwisthi Sattwika P, Najimi M, Sokal EM. Use of mesenchymal stem cells to treat liver fibrosis: current situation and future prospects. World J Gastroenterol. 2015; 21(3):742-58. [PubMed: 25624709]

37. Baligar P, Mukherjee S, Kochat V, Rastogi A, Mukhopadhyay A. Molecular and Cellular Functions Distinguish Superior Therapeutic Efficiency of Bone Marrow CD45 Cells Over Mesenchymal Stem Cells in Liver Cirrhosis. Stem Cells. 2015

38*. Pan F, Liao N, Zheng Y, Wang Y, Gao Y, Wang S, et al. Intrahepatic transplantation of adiposederived stem cells attenuates the progression of non-alcoholic fatty liver disease in rats. Mol Med Rep. 2015; 12(3):3725-33. This is the only recent study that evaluates stem cell therapy specifically for the treatment of non-alcoholic fatty liver disease, which is one of the main causes of cirrhosis in the United States. [PubMed: 26018346]

39. Lin PC, Chiou TW, Lin ZS, Huang KC, Lin YC, Huang PC, et al. A proposed novel stem cell therapy protocol for liver cirrhosis. Cell Transplant. 2015; 24(3):533-40. [PubMed: 25671337]

40. Okura H, Soeda M, Morita M, Fujita M, Naba K, Ito C, et al. Therapeutic potential of human adipose tissue-derived multi-lineage progenitor cells in liver fibrosis. Biochemical and biophysical research communications. 2015; 456(4):860-5. [PubMed: 25490388]

41. Jalan R, Gines P, Olson JC, Mookerjee RP, Moreau R, Garcia-Tsao G, et al. Acute-on chronic liver failure. J Hepatol. 2012; 57(6):1336-48. [PubMed: 22750750]

42. Moreau R, Jalan R, Arroyo V. Acute-on-Chronic Liver Failure: Recent Concepts. J Clin Exp Hepatol. 2015; 5(1):81-5. [PubMed: 25941435] 
43. Banares R, Catalina MV, Vaquero J. Liver support systems: will they ever reach prime time? Current gastroenterology reports. 2013; 15(3):312. [PubMed: 23392862]

44. Maiwall R, Maras JS, Nayak SL, Sarin SK. Liver dialysis in acute-on-chronic liver failure: current and future perspectives. Hepatol Int. 2014; 8(Suppl 2):505-13. [PubMed: 26201332]

45. Tsipotis E, Shuja A, Jaber BL. Albumin Dialysis for Liver Failure: A Systematic Review. Adv Chronic Kidney Dis. 2015; 22(5):382-90. [PubMed: 26311600]

46. Marangoni R, Bellati G, Castelli A, Romagnoli E. Development of high-efficiency molecular adsorbent recirculating system: preliminary report. Artif Organs. 2014; 38(10):879-83. [PubMed: 24392970]

47. Lee KC, Baker LA, Stanzani G, Alibhai H, Chang YM, Jimenez Palacios C, et al. Extracorporeal liver assist device to exchange albumin and remove endotoxin in acute liver failure: Results of a pivotal pre-clinical study. J Hepatol. 2015; 63(3):634-42. [PubMed: 25937432]

48. Banares R, Catalina MV, Vaquero J. Molecular adsorbent recirculating system and bioartificial devices for liver failure. Clin Liver Dis. 2014; 18(4):945-56. [PubMed: 25438293]

49. Hu C, Li L. In Vitro and In Vivo Hepatic Differentiation of Adult Somatic Stem Cells and Extraembryonic Stem Cells for Treating End Stage Liver Diseases. Stem Cells Int. 2015; 2015:871972. [PubMed: 26347063]

50. Jain E, Damania A, Shakya AK, Kumar A, Sarin SK. Fabrication of macroporous cryogels as potential hepatocyte carriers for bioartificial liver support. Colloids Surf B Biointerfaces. 2015; 136:761-71. [PubMed: 26519938]

51. Hoshiba T, Otaki T, Nemoto E, Maruyama H, Tanaka M. Blood-Compatible Polymer for Hepatocyte Culture with High Hepatocyte-Specific Functions toward Bioartificial Liver Development. ACS Appl Mater Interfaces. 2015; 7(32):18096-103. [PubMed: 26258689]

52. Wu C, Cao Y, Huo X, Li M. Simulation and experimental research on micro-channel for detecting cell status in bio-artificial liver. Technol Health Care. 2015; 23(Suppl 2):S365-71. [PubMed: 26410503]

53*. Yu CB, Pan XP, Yu L, Yu XP, Du WB, Cao HC, et al. Evaluation of a novel choanoid fluidized bed bioreactor for future bioartificial livers. World J Gastroenterol. 2014; 20(22):6869-77. This choanoid fluidized bed bioreactor may in the future be incorporated into bioartificial liver devices to increase and prolong hepatocyte viability. [PubMed: 24944477]

54. Deng F, Chen L, Zhang Y, Zhao S, Wang Y, Li N, et al. Development of a bioreactor based on magnetically stabilized fluidized bed for bioartificial liver. Bioprocess Biosyst Eng. 2015; 38(12): 2369-77. [PubMed: 26391509]

55*. Glorioso JM, Mao SA, Rodysill B, Mounajjed T, Kremers WK, Elgilani F, et al. Pivotal preclinical trial of the spheroid reservoir bioartificial liver. J Hepatol. 2015; 63(2):388-98. This device significantly improved survival in a porcine model of drug-induced acute liver failure, and demonstrated successful ammonia detoxification, as well as decrease of peak intracranial pressure. The spheroid structure protects hepatocytes from apoptosis, allowing them to remain viable and functional in suspension, and facilitates the use of a large cell mass. [PubMed: 25817557]

56**. Han B, Shi XL, Zhang Y, Gu ZZ, Yuan XW, Ren HZ, et al. No transmission of porcine endogenous retrovirus in an acute liver failure model treated by a novel hybrid bioartificial liver containing porcine hepatocytes. Hepatobiliary Pancreat Dis Int. 2015; 14(5):492-501. This study showed no transmission of porcine endogenous retrovirus into a canine model of acute liver failure treated with a bioartificial liver, suggesting that porcine hepatocyte-based bioartificial livers may be microbiologically safe. [PubMed: 26459725]

57. Lee SY, Kim HJ, Choi D. Cell sources, liver support systems and liver tissue engineering: alternatives to liver transplantation. Int J Stem Cells. 2015; 8(1):36-47. [PubMed: 26019753]

58. Nyberg S. Bridging the gap: advances in artificial liver support. Liver Transpl. 2012; 18:S10-S4. [PubMed: 22767444]

59. Kjaergard L, Liu J, Als-Nielsen B, et al. Artificial and bioartificial support systems for acute and acute-on-chronic liver failure: a systematic review. JAMA. 2003; 289:217-22. [PubMed: 12517233] 
60. Zheng Z, Li X, Li Z, Ma X. Artificial and bioartificial liver support systems for acute and acute-onchronic hepatic failure: A meta-analysis and meta-regression. Exp Ther Med. 2013; 6(4):929-36. [PubMed: 24137292]

61. van Wenum M, Chamuleau RA, van Gulik TM, Siliakus A, Seppen J, Hoekstra R. Bioartificial livers in vitro and in vivo: tailoring biocomponents to the expanding variety of applications. Expert Opin Biol Ther. 2014; 14(12):1745-60. [PubMed: 25366164] 


\section{Key points}

- Cell therapy for the treatment of chronic liver disease is based on cell transplantation or cell-based extracorporeal support devices for metabolic support while endogenous regeneration takes place, or as a bridge to liver transplantation.

- $\quad$ Primary human or porcine hepatocytes may be used, with current research focusing on improving expansion and engraftment, as well as finding alternative sources of cells.

- Stem cells are an alternative to the use of primary hepatocytes, with mesenchymal stem cells holding the greatest promise due to the added benefit of their anti-inflammatory, anti-apoptotic, immunomodulatory, and proproliferative effects.

- Bioartificial liver devices for the treatment of acute-on-chronic liver failure have yet to demonstrate survival benefit in humans, although the latest animal trials have shown encouraging results. 


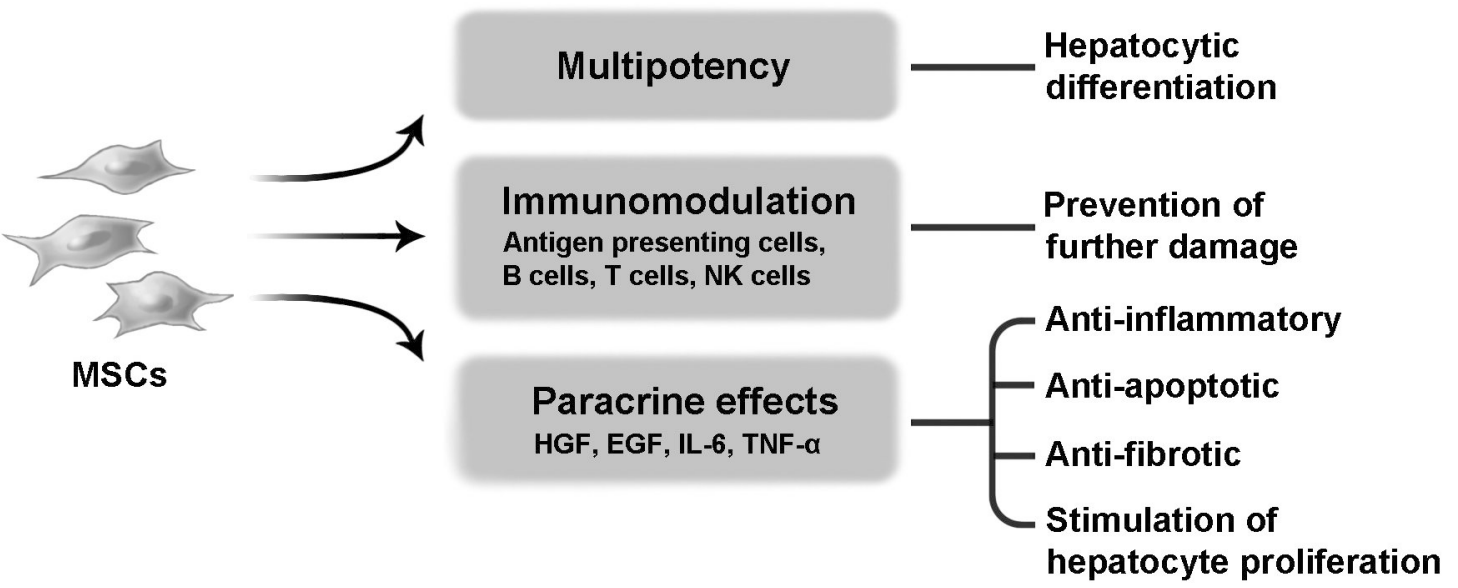

Figure 1. 


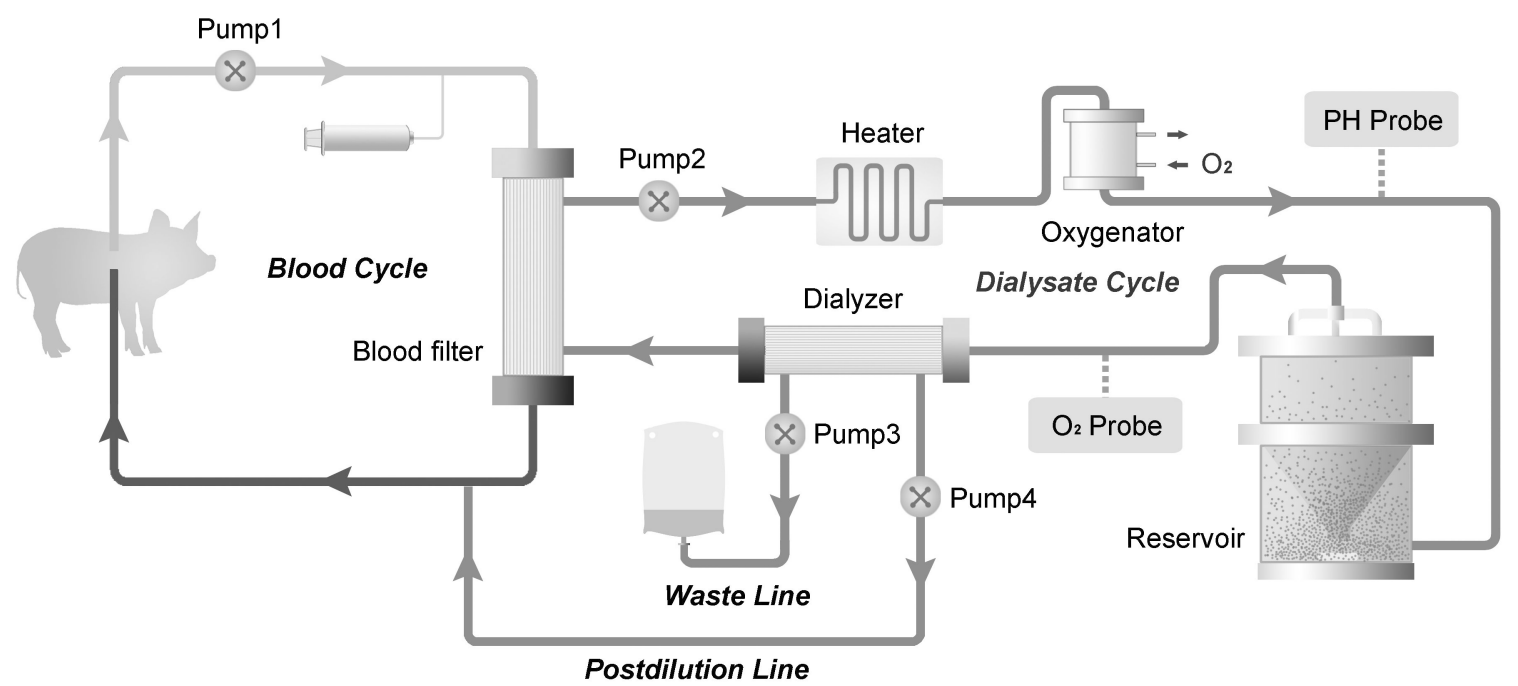

Figure 2. 


\section{Table 1}

Types of cell therapy based on cell line, source, and in vivo duration.

\begin{tabular}{ll}
\hline Types of Cell Therapy & Description \\
\hline $\begin{array}{ll}\text { Based on method of delivery } \\
\text { Cell transplantation }\end{array}$ & $\begin{array}{l}\text { Intrahepatic, intrasplenic or peripheral injection of whole cells } \\
\text { Use of whole cells in an extracorporeal support device }\end{array}$ \\
\hline Based on cell line & Mature hepatocytes \\
\hline $\begin{array}{l}\text { Primary cell } \\
\text { Stem cell }\end{array}$ & Hepatic, mesenchymal, adipose tissue-derived stem cells \\
\hline Based on cell source (6) & Human donor \\
\hline $\begin{array}{l}\text { Allogeneic } \\
\text { Autologous }\end{array}$ & $\begin{array}{l}\text { Patient } \\
\text { Animal donor, i.e. pig }\end{array}$ \\
\hline Based on cell in vivo half-life (7) \\
\hline $\begin{array}{l}\text { Transient dosing } \\
\text { Permanent implantation }\end{array}$ & $\begin{array}{l}\text { Days or weeks } \\
\text { Years }\end{array}$ \\
\hline
\end{tabular}

